\title{
The Emotional Dance with Depression: A Longitudinal Investigation of OULA for Depression in Women
}

\section{Tracy Hellem, Sung,Young-Hoon, Ferguson,Hayden, Hildreth, Laura}

This is the peer reviewed version of the following article which has been published in final form at 10.1016/j.jbmt.2020.05.007.

Hellem, T., Sung, Y. H., Ferguson, H., \& Hildreth, L. (2020). The Emotional Dance with Depression: A Longitudinal Investigation of OULA® for Depression in Women. Journal of Bodywork and Movement Therapies. 10.1016/j.jbmt.2020.05.007

(C) 2020 Journal of Bodywork and Movement Therapies. This manuscript version is made available under the CC-BY-NC-ND 4.0 license

https://creativecommons.org/licenses/by-nc-nd/4.0/

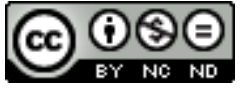

Made available through Montana State University's ScholarWorks 


\section{TITLE PAGE}

Title: The Emotional Dance with Depression: A Longitudinal Investigation of OULA ${ }^{\circledR}$ for Depression in Women

Authors: *Tracy Hellem, PhD, RN; tracy.hellem1@,montana.edu; College of Nursing, Montana State University, 32 Campus Drive \#7416, N. Corbin Hall, Room 123, Missoula, MT, 59812$7416 ; 406-243-2110$

Young-Hoon Sung, MD; yh.sung@utah.edu; Department of Psychiatry, Diagnostic

Neuroimaging, 383 Colorow Dr. University of Utah, Salt Lake City, UT, 801-587-1555

Hayden Ferguson, BA; hayden_ferguson@williamjames.edu; 1 Wells Ave, Newton, MA 02459; 406-750-0323

Laura Hildreth, PhD; lahildreth@gmail.com; Department of Mathematical Sciences, Montana

State University, PO Box 172400, Bozeman, MT, USA; 406-994-5358

*Corresponding Author 


\section{INTRODUCTION}

Depression is a psychiatric disorder that has a significant impact on individuals, families and communities. According to the World Health Organization (2018), more than 300 million people suffer from depression, and depression is the leading cause of disability across the world. One of the most well documented aspects of depression is that females are more likely to be depressed than males (Girgus \& Yang 2015; Parker et al 2014; Parker and Brotchie 2010; NolenHoeksema 2001). The risk of a woman developing depression at some point in her lifetime is 1.5 to 3 times higher than in men (Salk et al 2017; Kessler 2003; Blazer et al 1994).

There are many available treatments for depression but given that treatment for depression often starts in a primary care office (Amick et al 2015), antidepressant medications are usually the first approach used (Mojtabai and Olfson 2014). Over the past 20 years, antidepressant medications have expanded significantly; however approximately one- to twothirds of depressed patients do not respond to the initial antidepressant prescribed (Carek et al 2011; Gaynes et al 2009; Cain 2007). Moreover, rates of non-adherence to antidepressants have consistently been reported as greater than 40\% (Alekhya et al 2015; Sawada et al 2009; Bull et al 2002; Demyttenaere et al 2001), and recent research has shown that antidepressants may not be effective in people who live at altitude (Kanekar et al 2018). Finally, some patients prefer not to take antidepressants for a variety of reasons (Hanson et al 2016; Moradveisi et al 2014; Horne et al 2004). As a result, complementary and alternative approaches to treating depression are gaining popularity, and there is increasing scientific interest in the potential effectiveness of these modalities.

Physical activity or exercise serves as a cornerstone for the prevention of many chronic illnesses (Pedersen and Saltin 2015; Booth et al 2012), and over the past two decades, exercise is being prescribed to treat a variety of illnesses (Pedersen and Saltin 2015; Pedersen and Saltin 
2006). Exercise has been well studied as a treatment for depression, and consistent findings demonstrate that exercise has positive effects. For example, several systematic reviews (Daley 2008; Sjösten et al 2006; Stathopoulou et al 2006; Lawlor and Hopker 2001), a Cochrane metaanalysis (Mead et al 2008) and a Cochrane review (Cooney et al 2013) have reported reductions in depression with exercise. Further, some studies have documented that exercise is comparable to psychosocial approaches to treating depression, like cognitive behavioral therapy (Mead et al 2008; Daley 2008; Sjösten et al 2006; Stathopoulou et al 2006; Lawlor \& Hopker 2001), while others have indicated that exercise is similar to antidepressants for managing depression (Hoffman et al 2011; Blumenthal et al 2007; Babyak et al 2000).

Considering that dance has been shown to have beneficial effects on depression (Boing et al 2018; Murrock and Graor 2016; Adam et al 2016; McNeely et al 2015; Vankova et al 2014; Murrock and Graor 2014; Pinniger et al 2012), it is gaining interest as an exercise format to help relieve mood symptoms and improve body composition. A dance fitness program called OULA ${ }^{\circledR}$ (named after MissOULA, MT) was developed in recent years as a form of exercise that focuses on mind-body connection. Over the past several decades, there has been a growing body of research evidence in support of the importance of acknowledging the mind-body connection when treating illness (Dusek and Benson 2009; Littrell 2008; Gilbert 2003; Chiaramonte 1997). The concept of mind-body connection relates to recognizing the interconnection between mental states and physical processes (Littrell 2008), in addition to fostering opportunities to practice using tools to better cope with upsetting life events (Gilbert 2003). Mind-body exercise can be described as physical activity that is implemented with an inward mental focus with little attention on physical performance or physiological measures, e.g., target heart rate (La Forge 2016). 
OULA $^{\circledR}$ is choregraphed dance that can be used as a vehicle to process emotions through movement to songs that focus on connection with the self and others, femininity, power, determination, letting go and love; increase physical activity; as well as serve as a communal fitness format that is fun. Using exercises from older disciplines like Yoga, in addition to modern systems like Nia and dance/movement therapy, objectives of OULA ${ }^{\circledR}$ focus on enhancing breath awareness, expanding breath ability, experiencing the relationship between the physical, emotional and mental components of well-being, and feeling powerful. Available online and in nearly half the states in America, as well as three countries, OULA ${ }^{\circledR}$ is a high-energy dance workout to Top-40 American popular culture. A commonly used slogan in OULA ${ }^{\circledR}$ is, "it's not about how it looks, but about how it feels," encouraging participants to concentrate on how they feel while dancing and ignore how they look. In an Internet-based survey of OULA ${ }^{\circledR}$ participants, the authors report that the majority of OULA ${ }^{\circledR}$ participants are women and that the top two reasons for attending OULA ${ }^{\circledR}$ are for exercise and stress relief/improve mood (Hellem and Ferguson 2018).

Given the expanding body of evidence that both exercise (Cooney et al 2013; Daley 2008; Mead et al 2008; Sjösten et al 2006; Stathopoulou et al 2006; Lawlor and Hopker 2001) and dance (Boing et al 2018; Murrock and Graor 2016; Adam et al 2016; McNeely et al 2015; Vankova et al 2014; Murrock and Graor 2014; Pinniger et al 2012) are beneficial for improving depressive symptoms in a variety of populations, the aim of the current pilot study was to evaluate the dance fitness program OULA ${ }^{\circledR}$ as an intervention for depression in women diagnosed with major depressive disorder or persistent depressive disorder. Our primary hypothesis was that 12 -weeks of OULA ${ }^{\circledR}$ participation would be associated with a reduction in depression severity, measured by the Hamilton Depression Rating Scale. Our secondary 
hypotheses included that 12 -weeks of OULA ${ }^{\circledR}$ participation would be associated with a reduction in anxiety severity, measured by the Beck Anxiety Inventory and increase in happiness, measured by the Subjective Happiness Scale (SHS).

\section{MATERIALS AND METHODS}

\section{Participants}

A total of $n=70$ women were screened in person for participation and $n=53$ met eligibility criteria. Women were recruited using purposive sampling based on the following criteria for inclusion: between the ages of $18-70$ years, female gender, OULA ${ }^{\circledR}$ naïve (defined as attended 6 or less classes in the past 12 months), 17-item Hamilton Depression Rating Scale score of greater than 16 (i.e., moderate depression at a minimum [Furukawa et al 2007]), and Structured Clinical Interview for DSM-5 Disorders diagnosis of major depressive or persistent depressive disorder. Women were excluded if they were unable to provide adequate informed consent, if they had a clinically significant medical condition or illness that prevented them from participating in physical exercise, Structured Clinical Interview for DSM-5 Disorders diagnosis of bipolar disorder or schizophrenia, or current pregnancy (see Figure 1). If there was a concern about a potential participant's physical health, study personnel requested that she seek input from her primary care provider regarding the safety of participating in the study. Women with PTSD were not excluded from the current study because exercise (Shivakumar et al 2017; Whitworth \& Ciccolo 2016) and dance classes (Steinberg-Oren et al 2016) have been shown to relieve symptoms of PTSD (Shivakumar et al 2017; Whitworth \& Ciccolo 2016), as well as reduce stress and improve well-being (Steinberg-Oren et al 2016). Further, in a synthesis of dance/movement therapy and PTSD studies, Levine and colleagues (2015) found that a bodyoriented intervention is important for bringing awareness to the mind-body connection, 


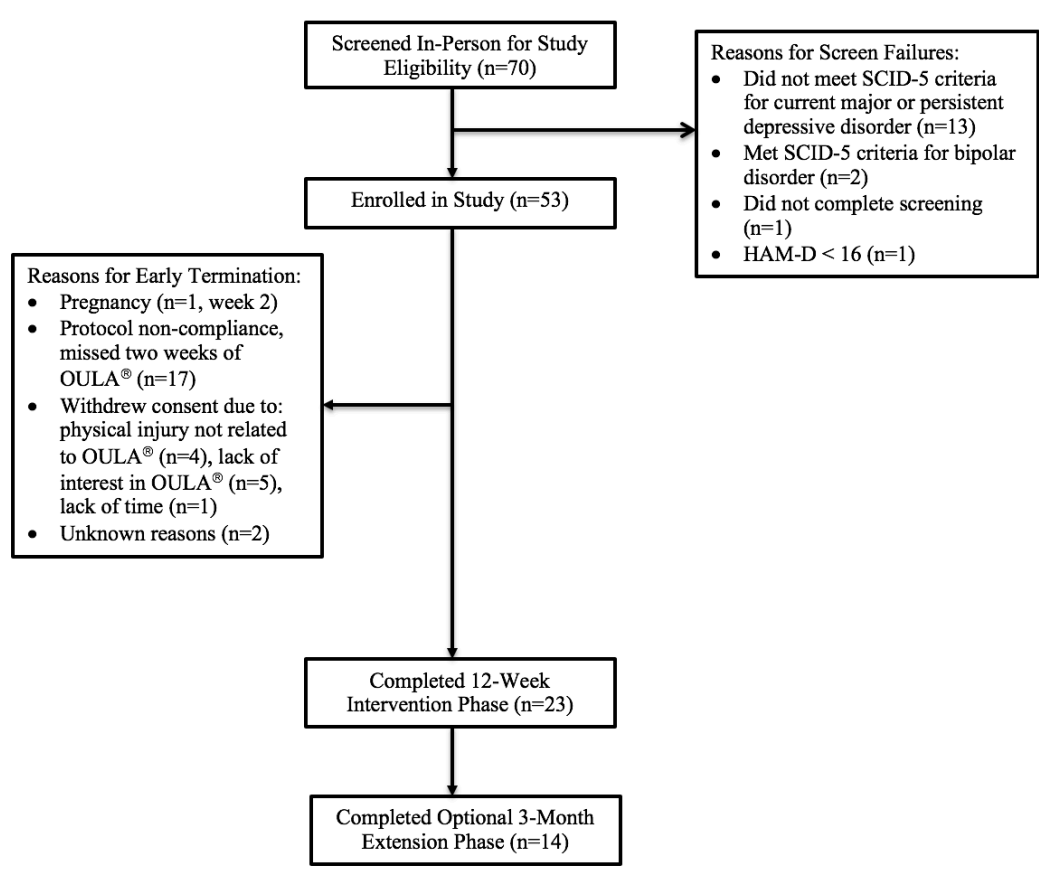

Figure 1. Flow Diagram of Participant Progress improving range of motion, as

well as for strengthening the

relationship with the self and

others through movement.

Recruitment occurred

using a variety of advertising

via social media, television,

radio and flyers. After learning

about the study, women

contacted the research team and

a preliminary phone screening

took place. For women who passed the phone screening, an in-person visit was scheduled where informed consent was obtained before any study procedures were initiated and the Structured Clinical Interview for DSM-5 Disorders and 17-item Hamilton Depression Rating Scale were administered to determine eligibility. The Structured Clinical Interview for DSM-5 Disorders was administered by project personnel who received extensive training on the use of the tool, and in situations when a diagnosis was unclear, a licensed clinical psychologist was consulted. Institutional Review Board (IRB) at a public university in the United States approved the study prior to data collection. All procedures performed in the study were in accordance with the ethical standards of the IRB and with the 1964 Helsinki declaration and its later amendments or comparable ethical standards.

\section{$\underline{\text { Intervention }}$}

Each OULA $^{\circledR}$ class consists of 16 choreographed songs, and instructors select songs for their playlist from a library of over 400 pre-choreographed songs. The choreography in OULA ${ }^{\circledR}$ 
uses the movement of dance with the intensity of an aerobic workout, in addition to using philosophies from Yoga, Nia (Rosas and Rosas 2014; Rosas and Rosas 1987) and dance/movement therapy (Tantia 2015). A new song is choregraphed 50 weeks out of the year, and usually the 10 most recent choregraphed songs are played at each class, with the idea that a participant can attend OULA ${ }^{\circledR}$ anywhere and be familiar with the most recent songs. A typical OULA $^{\circledR}$ class includes a warm-up song, two to four lower intensity songs (e.g., grounded and small movements), followed by eight high intensity songs (e.g., jumping, kicking, large movements), then a conditioning song (e.g., multiple squats or arm circles), a lower intensity song and ending with a cool down song.

After eligibility was determined, women were given the option to attend OULA ${ }^{\circledR}$ online for 4-weeks or initiate OULA ${ }^{\circledR}$ at a studio. Live OULA ${ }^{\circledR}$ classes are videotaped at a studio and uploaded to an online studio. The rationale for offering a 4-week online option was because many of the characteristics of depression, e.g., loss of interest, lack of motivation and energy, fatigue, low self-worth and confidence and psychomatic complaints, are barriers to exercising (Knapen et al 2015). Thus, introducing the women to OULA ${ }^{\circledR}$ in the comfort of their home had the potential to serve as a motivator and boost self-confidence before attending a studio.

The intervention period was a total of 12 weeks: 4-weeks of OULA ${ }^{\circledR}$ online or at a studio and 8-weeks of OULA ${ }^{\circledR}$ at a studio. Women were instructed to attend OULA ${ }^{\circledR}$ at least once per week. If women missed two consecutive weeks of OULA ${ }^{\circledR}$, they were terminated from the study. Attendance to $\mathrm{OULA}^{\circledR}$ at a studio was collected via self-report and verified with the attendance roster for each class provided by studio staff. After the 12-week intervention period, the women abstained from OULA $^{\circledR}$ for one week and attended a study visit 7-10 days after abstaining from OULA $^{\circledR}$ (week 14). Finally, a 3-month OULA ${ }^{\circledR}$ extension was offered to all participants (weeks 
14-26). This allowed women to continue OULA ${ }^{\circledR}$ for 3 -months at a studio free of cost. See Table 1 for a visual representation of the study flow and procedures.

\section{$\underline{\text { Outcome Measures }}$}

The primary outcome measure was depression severity and secondary outcome measures included anxiety severity and subjective happiness. Depression severity was evaluated using the previously well validated 17-item Hamilton Depression Rating Scale (HAM-D; Bagby et al 2004; Hamilton 1960). Each item of the 17-item HAM-D relates to a symptom of depression and is rated on a 3- or 5-point scale representing the severity for each item over the prior 7 days. Scores for the 17 items are summed to obtain a total HAM-D score where higher values indicate greater depressive symptoms. In this study, the 17-item HAM-D was administered by two raters (authors Dr. Tracy Hellem and Hayden Ferguson), and an inter-rater reliability analysis was performed to see the degree that the two raters consistently assigned a similar HAM-D score. This was assessed using a two-way mixed, consistency, average measures intra-class correlation (McGraw \& Wong 1996). The resulting intra-class coefficient was in the excellent range, ICC= .92 (Hallgren 2012). For this study, treatment response for the HAM-D was defined a priori as a decrease of $50 \%$ or more from baseline (Furukawa et al 2007).

Since depression and anxiety are highly comorbid (Moscati et al 2016), anxiety severity was examined as a secondary outcome. Further, in general, mental illness is a significant cause of unhappiness (Layard et al 2013). Thus, subjective happiness was examined as a secondary measure. To measure these outcomes, instruments that have been extensively validated were used: the Beck Anxiety Inventory (De Ayala et al 2005; Beck et al 1988) and the Subjective Happiness Scale (Mattei \& Schaefer 2004; Lyubomirsky \& Lepper 1999), respectively. The Beck Anxiety Inventory (BAI) is a self-administered scale that consists of 21 items relating to symptoms of anxiety that are scored from 0 (not at all) to 3 (severely). The score on the BAI is 
the sum of the scores on the 21 items with higher scores indicating higher levels of anxiety. Treatment response for the BAI was defined a priori as a decrease of $50 \%$ or more from baseline (Leyer et al 2006). Happiness, defined descriptively as a person's psychological state (Phillips et al 2017), was measured using the Subjective Happiness Scale (SHS), a self-administered tool that consists of four items measured on a seven point scale from 1 to 7 . The scores on the four items are averaged to obtain the SHS score with the fourth item being reverse-coded. The same rater averaged each SHS score. Considering that happiness is a subjective state of well-being (Mattei and Schaefer 2004), as opposed to a disorder, treatment response was not defined.

During the first four weeks of the study, the 17-item HAMD, BAI and SHS were collected at weeks 2 and 4, and then weekly during weeks 5-14. A final study visit was scheduled for week 26 for women who elected to enter the optional 3-month OULA ${ }^{\circledR}$ phase (see Table 1).

Table 1. Summary of Design and Procedures

\begin{tabular}{|c|c|c|c|c|c|c|}
\hline & Screening & Weeks $2 \& 4$ & Weeks 5-12 & Week 13 & Weeks 14 - 25 & Week 26 \\
\hline $\begin{array}{l}\text { Informed Consent, } \\
\text { Demographics }\end{array}$ & $\mathbf{X}$ & & & & & \\
\hline $\begin{array}{l}\text { Structured Clinical Interview } \\
\text { for DSM-5 Disorders }\end{array}$ & $\mathbf{X}$ & & & & & \\
\hline $\begin{array}{l}\text { Clinical Scales: HAM-D, } \\
\text { BAI, SHS }\end{array}$ & $\mathbf{X}$ & $\mathbf{X}$ & $\mathbf{X}$ & $\mathbf{X}$ & & $\mathbf{X}$ \\
\hline Weight & $\mathbf{X}$ & $\mathbf{X}$ & $\mathbf{X}$ & $\mathbf{X}$ & & $\mathbf{X}$ \\
\hline Current Medications & $\mathbf{X}$ & $\mathbf{X}$ & $\mathbf{X}$ & $\mathbf{X}$ & & $\mathbf{X}$ \\
\hline $\begin{array}{l}\text { OULA }^{\circledR} \text { Online or Studio } \\
\text { Attendance }\end{array}$ & & $\mathbf{X}$ & & & & \\
\hline OULA $^{\circledR}$ Studio Attendance & & $\mathbf{X}$ & $\mathbf{X}$ & & $\mathbf{X}$ & $\mathbf{X}$ \\
\hline $\begin{array}{l}\text { OULA }^{\circledR} \text { Attendance } \\
\text { Frequency }\end{array}$ & & $\mathbf{X}$ & $\mathbf{X}$ & $\mathbf{X}$ & & $\mathbf{X}$ \\
\hline
\end{tabular}

HAM-D = Hamilton Depression Rating Scale; BAI = Beck Anxiety Inventory; SHS = Subjective Happiness Scale

\section{$\underline{\text { Statistical Analyses }}$}


This single arm study was a pilot study, and a power analysis to determine number of participants needed for statistical significance was not performed (Leon et al 2011). Descriptive data are presented as mean \pm standard deviation for continuous variables and frequency percentages for categorical variables.

Analyses for change in HAM-D, BAI and SHS scores were performed using a linear mixed effects model repeated measures analysis, which is capable of handling missing data and time varying covariates (Mallinckrodt et al 2003). Time was included as a fixed factor and subject was treated as a random factor. Sidak correction, a method to compensate for multiple comparisons (West et al 2006), was used to control for Type I error for all linear mixed effects repeated model analyses. Finally, a paired t-test was performed for each outcome variable to evaluate mean change in outcome scores between weeks 13 and 14 . Women abstained from OULA $^{\circledR}$ during week 13 , and we were interested in learning if outcome scores significantly changed after one week of no OULA ${ }^{\circledR}$. Cohen's d was used as an effect size.

Splitting the intervention into two phases may have introduced a confounding factor given the companionship and attention from OULA ${ }^{\circledR}$ instructors and other OULA ${ }^{\circledR}$ attendees at a studio. To understand if a covariate was introduced, considering the unequal and small group sizes (week 2: $\mathrm{n}=15$ online versus $\mathrm{n}=31$ studio, week 4: $\mathrm{n}=5$ online, $\mathrm{n}=31$ studio) (Zimmerman 1987), Mann Whitney U was used to compare outcome (HAM-D, BAI and SHS) scores by group (online versus studio attendance) for weeks 2 and 4.

With respect to linear mixed effects repeated model assumptions, visual inspection did not reveal any obvious deviations from linearity of the residual plot, homoscedasticity or normality of residuals. The assumptions for paired t-test were also reasonably met. The impact of dropouts on the analyses were examined. Because results did not change substantially, the results presented include all observations as opposed to only complete observations. A significance 
level of equal to or less than 0.05 was used for directional hypothesis testing, and statistical analyses were conducted through the Statistical Package for the Social Science 25.

\section{$\underline{\text { RESULTS }}$}

\section{$\underline{\text { Baseline Characteristics }}$}

The characteristics of the eligible subjects $(n=53)$ at the time of screening are displayed in Table 2 . The average age was $41.83 \pm 13.85$ years. The majority of subjects were married $(n=19$, $35.9 \%)$, divorced/separated $(n=14,26.4 \%)$ or living with their partner $(n=10,18.9 \%)$. Over half of the subjects had children $(n=32,60.4 \%)$, and the sample was relatively homogeneous in terms of race, as $n=51$ of the subjects $(96.2 \%)$ were white/Caucasian. Two of the subjects $(3.8 \%)$ reported being Hispanic or Latino.

\begin{tabular}{|c|c|}
\hline Characteristic & \\
\hline Mean age (SD) & $41.83(13.85)$ \\
\hline \multicolumn{2}{|l|}{ Race, N (\%) } \\
\hline Caucasian & $51(96.2 \%)$ \\
\hline American Indian & $1(1.9 \%)$ \\
\hline Native Hawaiian or Pacific Islander & $1(1.9 \%)$ \\
\hline \multicolumn{2}{|l|}{ Ethnicity, N (\%) } \\
\hline Hispanic or Latino & $51(96.2 \%)$ \\
\hline \multicolumn{2}{|l|}{ Marital Status, N (\%) } \\
\hline Married & $19(35.8 \%)$ \\
\hline Widowed & $2(3.8 \%)$ \\
\hline Divorced & $12(22.6 \%)$ \\
\hline Separated & $2(3.8 \%)$ \\
\hline Never Married & $8(15.1 \%)$ \\
\hline Living With Partner & $10(18.9 \%)$ \\
\hline Children, $\mathrm{N}(\%)$ & $32(60.4 \%)$ \\
\hline \multicolumn{2}{|l|}{ Employment Status, N (\%) } \\
\hline Employed & $30(56.6 \%)$ \\
\hline Unemployed & $6(11.4 \%)$ \\
\hline Retired & $5(9.4 \%)$ \\
\hline Disabled & $2(3.8 \%)$ \\
\hline Homemaker & $5(9.4 \%)$ \\
\hline Student & $5(9.4 \%)$ \\
\hline \multicolumn{2}{|l|}{ Education Level, N (\%) } \\
\hline Graduated high school or GED & $10(18.9 \%)$ \\
\hline Part College & $8(15.1 \%)$ \\
\hline Graduated 2 year college & $14(26.4 \%)$ \\
\hline Bachelor's Degree & $15(28.3 \%)$ \\
\hline Master's Degree & $3(5.7 \%)$ \\
\hline Professional Degree & $1(1.9 \%)$ \\
\hline Doctoral Degree & $2(3.8 \%)$ \\
\hline \multicolumn{2}{|l|}{ Annual Income, N (\%) } \\
\hline$<\$ 15,000$ & $7(13.2 \%)$ \\
\hline$\$ 15,001-\$ 25,000$ & $11(20.8 \%)$ \\
\hline$\$ 25,001-\$ 35,000$ & $10(18.9 \%)$ \\
\hline$\$ 35,001-\$ 45,000$ & $8(15.1 \%)$ \\
\hline$\$ 45,001-\$ 55,000$ & $3(5.7 \%)$ \\
\hline
\end{tabular}


$\$ 55,001-\$ 65,000$

$\$ 65,001-\$ 75,000$

$\$ 75,001-\$ 85,000$

$\$ 85,001-\$ 95,000$

$\$ 100,000+$

Current Participation in Exercise, N (\%)

Type of Current Exercise, N (\%)

Yoga

Pilates

Running

Walking

Hiking

Swimming

Lifting Weights

Biking

Dance Classes

Frequency of Current Exercise, N (\%)

1 Day Per Week

2-3 Days Per Week

4-6 Days Per Week

7 Days Per Week

Family History of Depression, N (\%)

History of Taking Antidepressants, N (\%)

Currently Taking an Antidepressant, N (\%)

Currently Taking an Anxiolytic, N (\%)

How Many Different Antidepressants Tried, N (\%)

One

Two to three

Four to five

Six or More

Reasons for Terminating Antidepressants, N (\%)

Did Not Work

Side Effects

Loss of Insurance

Stopped Feeling Depressed

Not Sure Why Antidepressant Stopped

Other

SCID-V Diagnoses, N (\%)

Major Depressive Disorder (MDD),

Lifetime

MDD, Last Month

MDD, Last Month Severity

Mild

Moderate

Severe

MDD, Recurrent

MDD, Seasonal Pattern

Persistent Depressive Disorder (PDD),

Lifetime

PDD Past 2 Years

PDD Early Onset

Premenstrual Disorder Past 12 Months

Alcohol Use Disorder, Lifetime

Alcohol Use Disorder, Last Month

Sedative Use Disorder, Lifetime

Stimulant Use Disorder, Lifetime

Stimulant Use Disorder, Last Month

Opioid Use Disorder, Lifetime

Panic Disorder, Lifetime

Panic Disorder, Last Month

Agoraphobia, Lifetime

Agoraphobia, Last Month

Social Phobia, Lifetime

Social Phobia, Last Month

Generalized Anxiety Disorder, Lifetime
$3(5.7 \%)$

$2(3.8 \%)$

$1(1.9 \%)$

$1(1.9 \%)$

$5(9.4 \%)$

$26(49.1 \%)$

$5(9.4 \%)$

$1(1.9 \%)$

$4(7.5 \%)$

$15(28.3 \%)$

$10(18.9 \%)$

$1(1.9 \%)$

$6(11.3 \%)$

$2(3.8 \%)$

$1(1.9 \%)$

$1(1.9 \%)$

$10(18.9 \%)$

$13(24.5 \%)$

$4(7.5 \%)$

$46(86.8 \%)$

$44(83.0 \%)$

$29(54.7 \%)$

$1(1.9 \%)$

$8(15.1 \%)$

$22(41.5 \%)$

$12(22.6 \%)$

$2(3.8 \%)$

$23(43.4 \%)$

$25(47.2 \%)$

$3(5.7 \%)$

$6(11.3 \%)$

$1(1.9 \%)$

$6(11.3 \%)$

$50(94.3 \%)$

$45(84.9 \%)$

$4(7.5 \%)$

$41(77.4 \%)$

$5(9.4 \%)$

$40(75.5 \%)$

$3(5.7 \%)$

$29(54.7 \%)$

$26(49.1 \%)$

$21(39.6 \%)$

$3(5.7 \%)$

$9(17.0 \%)$

$1(1.9 \%)$

$1(1.9 \%)$

$5(9.4 \%)$

$2(3.8 \%)$

$2(3.8 \%)$

$32(60.4 \%)$

$16(30.2 \%)$

$7(13.2 \%)$

$2(3.8 \%)$

$22(41.5 \%)$

$20(37.7 \%)$

$36(67.9 \%)$ 
Generalized Anxiety Disorder, Last Month

Substance-Induced Anxiety Disorder,

Lifetime

Obsessive Compulsive Disorder, Lifetime

Obsessive Compulsive Disorder, Last Month

PTSD, Lifetime

PTSD, Last Month

Currently Receiving Psychosocial Treatment, N (\%)

Mean HAMD score (SD)

Mean BAI score (SD)

Mean SHS score (SD)

$\mathrm{SD}=$ standard deviation
$29(54.7 \%)$

$1(1.9 \%)$

$3(5.7 \%)$

$1(1.9 \%)$

$12(22.6 \%)$

$7(13.2 \%)$

$17(32.1 \%)$

$20.08(2.87)$

$19.87(11.51)$

$3.39(1.12)$

The majority of subjects were currently employed $(n=30,56.6 \%)$, and had obtained a bachelor's degree or less $(n=47,88.7 \%)$. At baseline, nearly half of the women $(n=26)$ endorsed that they currently participated in regular exercise. With respect to DSM-5 diagnoses, $84.9 \%$ $(n=45)$ met diagnostic criteria for current major depressive disorder, and $n=26(49.1 \%)$ endorsed criteria for persistent depressive disorder. A little over half, 54.7\% $(n=29)$, of the women were being treated with an antidepressant at baseline. Forty-five subjects (84.9\%) met DSM-5 criteria for an anxiety disorder in the past six months, and $n=7(13.2 \%)$ had current Post Traumatic Stress Disorder.

$\underline{\text { Screening, Attendance, and Attrition }}$

Over the course of 12 months, we screened a total of $n=147$ women by phone and invited $\mathrm{n}=94$ women to attend an informed consent and formal screening visit. Of these $n=94$ women, $\mathrm{n}=70$ attended the in-person screening visit. As previously mentioned, there was a total of $\mathrm{n}=53$ women enrolled in the study. Of these women, $n=23$ completed the 12 -week intervention phase (43.4\% retention rate) and $n=14$ completed the optional 3-month extension phase. Figure 1 outlines reasons for early termination, with protocol non-compliance being the primary reason $(n=17)$. The majority of the early terminations occurred during weeks 2 and 4.

As a reminder, women were offered optional online OULA ${ }^{\circledR}$ for the first four weeks of the intervention period. Twenty-eight percent $(n=15)$ of the women elected to attend OULA ${ }^{\circledR}$ online during the first two weeks of the intervention period and $9.4 \%(n=5)$ of the sample 
attended OULA ${ }^{\circledR}$ online for weeks three and four of the intervention period. The rest of the women $(n=31)$ attended OULA ${ }^{\circledR}$ at a studio from the beginning of the intervention period.

During the intervention period, on average, participants reported attending $14.72 \pm 13.03$

OULA $^{\circledR}$ classes (on average 1.22 classes per week). Attendance data from the studio indicate that, on average, women attended $11.48 \pm 11.90$ classes. Of interest, there was not a strategy for validating online classes. Further, $22.7 \%(n=10)$ of the sample attended at least one OULA ${ }^{\circledR}$ class at a location other than the studio, and these classes were also not validated.

\section{HAM-D}

Table 3 provides summary statistics of HAM-D at each time point while Figure 2 visually displays this information. At the time of screening, the average HAM-D score was $20.08 \pm 2.87$, indicating a moderately depressed sample (Furukawa et al 2007). At the end of the intervention period, the average HAM-D score decreased to $6.48 \pm 4.73$, indicating "borderline" depression (Furukawa et al., 2007). The average HAM-D score spiked during week 14 likely because the women abstained from OULA ${ }^{\circledR}$ the prior week.

Table 3: Average Hamilton Depression Rating Scores at Each Data Collection Time Point

\begin{tabular}{|l|l|l|l|l|l|l|l|l|l|l|l|l|l|l|}
\hline Week & 0 & 2 & 4 & 5 & 6 & 7 & 8 & 9 & 10 & 11 & 12 & 13 & 14 & 26 \\
\hline Mean & 20.08 & 15.74 & 14.36 & 12.09 & 9.43 & 10.04 & 9.11 & 8.85 & 8.29 & 7.91 & 6.91 & 6.48 & 10.87 & 5.93 \\
\hline SD & 2.87 & 4.28 & 5.91 & 5.71 & 5.89 & 6.38 & 6.01 & 5.02 & 4.07 & 3.36 & 4.72 & 4.73 & 6.11 & 4.23 \\
\hline n & 53 & 46 & 36 & 33 & 28 & 27 & 28 & 26 & 24 & 23 & 23 & 23 & 23 & 14 \\
\hline
\end{tabular}

$\mathrm{SD}=$ Standard deviation

The linear mixed effects repeated measures model analysis revealed a statistically significant reduction in mean HAM-D scores from baseline as early as week 2 and maintained through week $26(p=.009$ for week 2 compared to baseline and $p=.000$ for all other weeks compared to baseline). Further, the results of a paired t-test examining change in mean HAM-D scores between weeks 13 and 14 indicated a statistically significant increase in HAM-D scores at week 14 compared to week 13, $t(22)=3.413 . p=.002, d=0.71$. Finally, the results of Mann 
Figure 2: Average Hamilton Depression Rating Scale (HAM-D) Scores Over Time

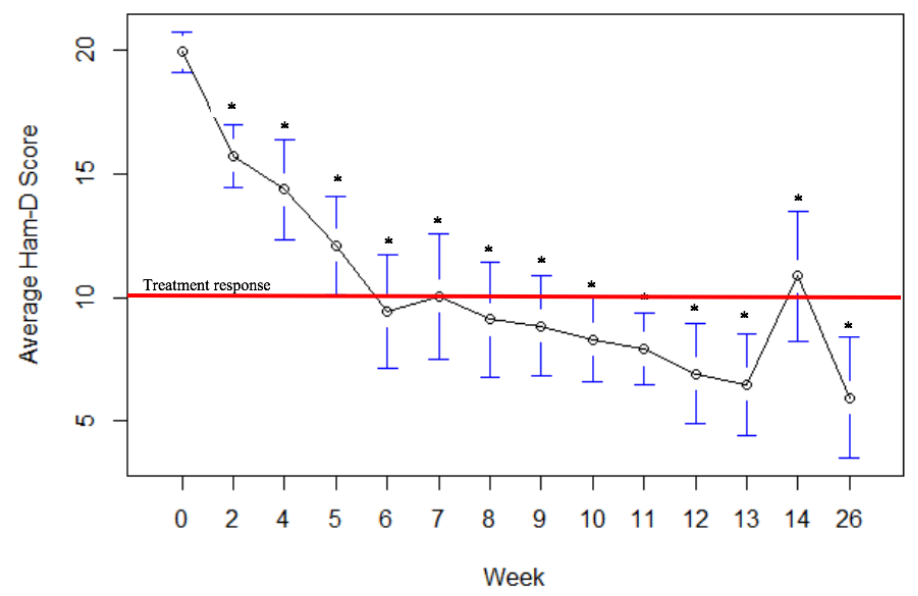

Circles denote means and bars indicate $95 \%$ confidence intervals

Asterisks indicate statistically significant reduction in score compared to baseline

Participants attended OULA $^{\circledast}$ from weeks $1-13$, then abstained from OULA ${ }^{\circledast}$ during week 13. OULA ${ }^{\circledast}$ was resumed weeks $14-26$ (optional OULA ${ }^{\circledast}$ extension phase).

$=30.50, \mathrm{p}=.031$.

\section{$\underline{\mathrm{BAI}}$}

Table 4 provides summary statistics of BAI scores at each time point while Figure 3 displays this information visually. At the time of screening, average BAI was $19.87 \pm 11.51$ indicating a low to moderately anxious sample (Leyer et al 2006). At the end of the intervention period, average BAI score was $7.33 \pm 6.20$. Table 4 and Figure 2 display that average BAI scores decrease throughout the study with the greatest decreases occurring during the first five weeks. One notable exception is during week 14 when average BAI score spikes. During this week of the study data were collected but OULA ${ }^{\circledR}$ was not offered, which may account for this spike.

Table 4: Average Beck Anxiety Score at Each Data Collection Time Point

\begin{tabular}{|l|l|l|l|l|l|l|l|l|l|l|l|l|l|l|}
\hline Week & 0 & 2 & 4 & 5 & 6 & 7 & 8 & 9 & 10 & 11 & 12 & 13 & 14 & 26 \\
\hline Mean & 19.87 & 16.63 & 15.03 & 11.45 & 10.57 & 8.41 & 9.82 & 9.92 & 9.13 & 8.91 & 9.17 & 7.33 & 10.43 & 7.43 \\
\hline SD & 11.51 & 8.21 & 9.45 & 9.37 & 8.70 & 8.34 & 9.58 & 10.04 & 6.83 & 7.79 & 8.89 & 6.20 & 6.33 & 6.09 \\
\hline $\mathrm{n}$ & 53 & 46 & 36 & 33 & 28 & 27 & 28 & 26 & 24 & 23 & 23 & 23 & 23 & 14 \\
\hline
\end{tabular}

The linear mixed effects repeated measures model analysis revealed a statistically significant reduction in mean BAI scores from baseline starting at week 5 and maintained through week 26 ( $p<.05$ for weeks 5-26 compared to baseline). Additionally, the results of a 
Figure 3: Average Change in Beck Anxiety Inventory (BAI) Scores Over Time

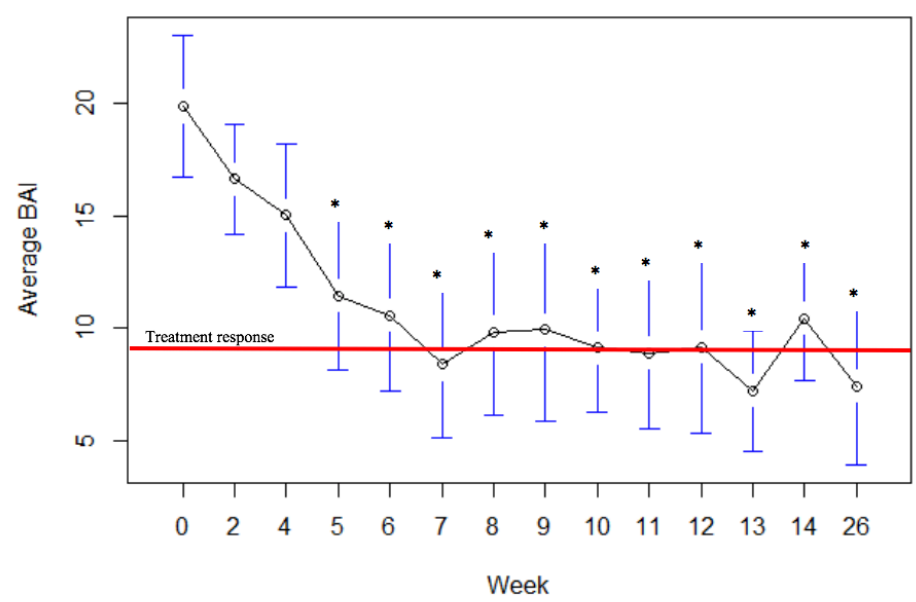

Circles denote means and bars indicate $95 \%$ confidence intervals

Asterisks indicate statistically significant reduction in score compared to baseline

Participants attended OULA ${ }^{\circledast}$ from weeks $1-13$, then abstained from OULA ${ }^{\circledast}$ during week 13 . OULA ${ }^{\circledast}$ was

resumed weeks $14-26$ (optional OULA ${ }^{\circledast}$ extension phase). paired t-test evaluating change in mean

BAI scores between weeks 13 and 14

demonstrated a statistically significant

increase in scores at week 14 compared

to week 13: $\mathrm{t}(22)=3.217 . \mathrm{p}=.036, \mathrm{~d}=$

0.47. Finally, the results of Mann

Whitney U tests to compare BAI

scores by group (online versus studio)

for weeks $2(p=.227)$ and $4(p=.963)$

were insignificant.

$\underline{\text { SHS }}$

Table 5 provides the summary statistics of SHS for each week of the study which is visually displayed in Figure 4. These summary statistics indicate that average SHS increased throughout the course of the study. The greatest increases in SHS occurred during the first seven weeks of the study with slight changes occurring after week seven. At baseline, the average SHS score was $3.39 \pm 1.12$, and the mean SHS score was $4.50 \pm 1.13$ at the end of the intervention phase.

Table 5: Average Subjective Happiness Scale Scores at Each Data Collection Time Point

\begin{tabular}{|l|l|l|l|l|l|l|l|l|l|l|l|l|l|l|}
\hline Week & 0 & 2 & 4 & 5 & 6 & 7 & 8 & 9 & 10 & 11 & 12 & 13 & 14 & 26 \\
\hline Mean & 3.39 & 3.61 & 3.86 & 3.97 & 4.04 & 4.29 & 4.21 & 4.28 & 4.44 & 4.38 & 4.30 & 4.50 & 4.26 & 4.70 \\
\hline SD & 1.12 & 1.00 & 1.05 & 0.96 & 1.08 & 1.10 & 1.09 & 1.15 & 1.16 & 1.08 & 1.05 & 1.13 & 1.30 & 1.19 \\
\hline n & 53 & 46 & 36 & 33 & 28 & 27 & 28 & 26 & 24 & 23 & 23 & 23 & 23 & 14 \\
\hline
\end{tabular}

$\mathrm{SD}=$ Standard deviation

The linear mixed effects repeated measures model analysis revealed a statistically significant increase in mean SHS scores from baseline at week $7(p=.05)$, week $10(p=.01)$, week $11(\mathrm{p}=.03)$, week $13(\mathrm{p}=.01)$ and week $26(\mathrm{p}=.01)$. Moreover, the results of a paired t- 
Figure 4: Average Change in Subjective Happiness Scale (SHS) Scores Over Time

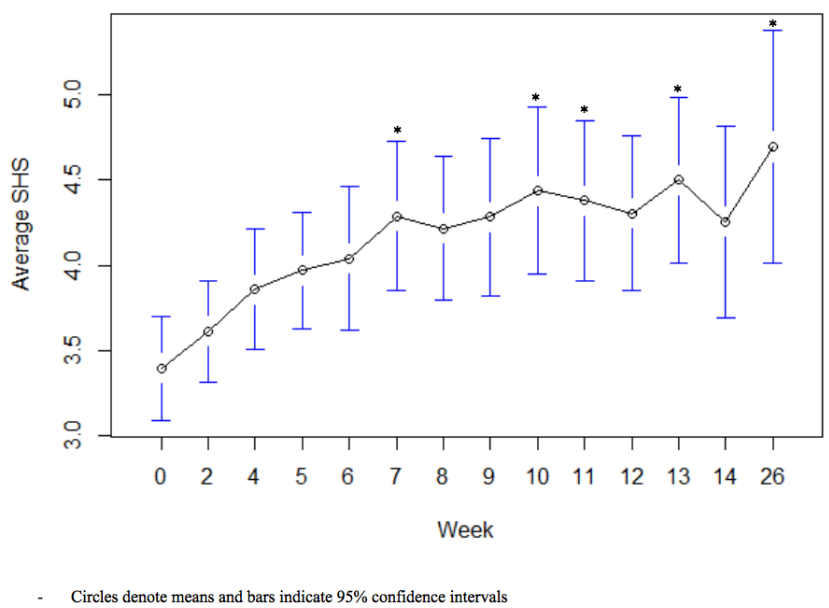

Circles denote means and bars indicate $95 \%$ confidence intervals
Asterisks indicate statistically significant increase in score compared to baseline Participants attended OULA ${ }^{\oplus}$ from weeks $1-13$, weeks $14-26$ (optional OULA ${ }^{\circledast}$ extension phase) test examining change in mean SHS scores between weeks 13 and 14 revealed no change: $t(22)=-.245, p=.217$. Finally, the results of Mann Whitney U tests to compare SHS scores by group (online versus studio) for weeks $2(p=.972)$ and 4 $(p=.597)$ were insignificant.

With respect to missing data, $n=6$ subjects missed one week of data collection due to traveling or an illness. None of the participants withdrew consent from the study due to injuries from OULA ${ }^{\circledR}$. Five participants withdrew consent because of a lack of interest in participating in OULA $^{\circledR}$.

\section{$\underline{\text { DISCUSSION }}$}

In this paper, results of what is, to the best of our knowledge, the first study evaluating OULA $^{\circledR}$ as an intervention for depression in women are reported. In this pilot study, women participated in at least once per week OULA ${ }^{\circledR}$ for 12 -weeks and then abstained from OULA ${ }^{\circledR}$ for one week. Depression and anxiety severity, as well as subjective happiness were measured every other week for the first month, weekly through the intervention period and after one week of abstaining from OULA ${ }^{\circledR}$. A consistent reduction in depression from baseline through the end of the 12-week intervention period was noted, while an increase in depressive symptoms was found after the week of abstinence. A reduction in anxiety severity was noted at week 5 through the end of the 12-week intervention period, with an increase in anxiety symptoms after a week of abstaining from OULA ${ }^{\circledR}$. There was not a consistent change in subjective happiness over the 
course of the intervention period. Finally, an optional 3-months of additional OULA ${ }^{\circledR}$ was offered to all participants after completing the week of abstinence from OULA ${ }^{\circledR}$. Attendance to this optional phase of the study was low, but a decrease in depression and anxiety and increase in subjective happiness was noted from the end of the optional phase compared to baseline.

The results of this study add to a growing body of literature that dance and dance/ movement therapy are associated with improvements in psychiatric clinical symptoms. This is likely due to several factors: first, from the synchronizing pleasurable experience of music and movement - when the brain's reward centers are stimulated by music (Vuilleumier and Trost 2015) while brain sensory and motor circuits are also activated (Leisman et al 2016). Second, from the general well-known benefits of exercise (Pederson and Saltin 2015; Vina et al 2012). Third, from the sense of being part of a community (Fisher et al 2015). Finally, there are mindbody aspects of OULA ${ }^{\circledR}$ that focus on learning to move through emotions and practice selfacceptance that likely contribute to improvements in psychiatric symptoms.

The observation made in our study with respect to change in depression is in accordance with several longitudinal studies on the effect of some form of dance or dance/movement therapy on depression (López-Rodríguez et al 2017; Gao et al 2016; Pylvänäinen et al 2015; Murrock and Graor 2014; Punkanen et al 2014; Vankova et al 2014; Pinniger et al 2013; Baptista et al 2012; Pinniger et al 2012; Akandere and Demir 2011; Eyigor et al 2009; Hui et al 2009; Quiroga Murcia et al 2009; Haboush et al 2006; Jeong et al 2005; Noreau et al 1995). Fewer studies have evaluated anxiety as an outcome. However, similar to the present study, anxiety has been shown to improve with a dance-related intervention (Erwin-Grabner et al 1999; Noreau et al 1995), although Erwin-Grabner et al. (1999) and Noreau et al. (1995) compared baseline anxiety to end of intervention anxiety; thus, the exact onset of when relief from anxious symptoms occurred is unknown. 
One potential explanation for the discrepancy in improvement in anxiety severity relative to depression severity is that nearly half the participants were currently taking an antidepressant at study entry and only one participant was taking an anxiolytic. Perhaps OULA ${ }^{\circledR}$ has an adjunctive effect to pharmacotherapy, although this thought warrants further investigation with a randomized controlled study. Another consideration is that, similar to some psychotropics, the anxiolytic effect of OULA ${ }^{\circledR}$ might take up to four weeks until improvement in symptoms is noted. Finally, the current sample attended, on average, OULA ${ }^{\circledR} 1.22$ times per week during the intervention period. It is possible that the attendance frequency was not high enough to alleviate anxious symptoms, albeit, Viana and colleagues (2017) found a significant decrease in state anxiety in healthy women after a single session of the exergame Zumba. One difference between the current study and Viana et al.'s (2017) study is that the latter recruited healthy women, whereas we included women with a DSM-5 diagnosis of major depressive or persistent depressive disorder, and depression is known to complicate treating anxiety (Ballenger 2000). Moreover, Viana and colleagues (2017) investigated the dance exergame Zumba, a type of gaming exercise that involves Latin dancing, while OULA ${ }^{\circledR}$ in the current study was attended via online or in person. Also, state anxiety was measured pre- and post-single session of the exergame Zumba, and we collected anxiety severity over time.

It was surprising to learn that subjective happiness was not consistently increased in this study given that there is some evidence of a link between happiness and depression (Silva and Figueiredo-Braga 2018; Layard et al 2013). In contrast to this evidence, some research shows that happiness and depression are two separate variables rather than being on a continuum (Keyes et al 2010; Keyes 2005), meaning that the absence of symptoms of depression does not equal the presence of happiness (Keyes et al 2010). Indeed, one study shows that increasing well-being (happiness) predicts a decline in depression (Keyes et al 2010). Further, it has been 
argued that happiness is challenging to define, in addition to measure (Kringelbach and Berridge 2011).

While there is a paucity of studies that used dance for happiness, there are a few controlled studies that measured quality of life or well-being associated with dance/movement therapy (Bräuninger 2012; Meekums et al 2012) or dance fitness (Delextrat et al 2016; Domene et al 2016). One of these studies recruited healthy women (Delextrat et al 2016), and another recruited adults with stress but no psychiatric illness (Bräuninger 2012). The third study included obese women (Meekums et al 2012), but psychiatric status was not reported, and, finally, the last study examined overweight, physically inactive women (Domene et al 2016), but psychiatric status was not known. These studies consistently demonstrated an increase in quality of life (Bräuninger 2012) and well-being (Delextrat et al 2016; Domene et al 2016; Meekums et al 2012) with dance/movement therapy or dance fitness in the treatment groups compared to controls. Considering that individuals diagnosed with depression, anxiety and comorbid mood disorders generally feel less happy than controls (Spinhoven et al 2015), the absence of or lack of knowledge regarding psychiatric illness in these studies might explain the increase in quality of life or well-being, yet, consistent changes in happiness were not documented in the present study.

The findings from this study could be useful for mental health professionals or primary care providers who treat depression and anxiety in women. While this study has several limitations to consider, which are discussed below, referring women to engage in dance fitness is not likely going result in harm. Indeed, given that many people do not respond to the conventional approach of treating depression, i.e., pharmacotherapy, or they are unable to tolerate side effects, suggesting a complementary and alternative approach that increases physical activity, as well as helps with processing emotions, is a very attractive option. 


\section{LIMITATIONS}

This study suggests OULA ${ }^{\circledR}$ is associated with a reduction in depression and anxiety severity. However, there are several limitations that merit discussion. First, the attrition rate in this study was much higher than expected. Namely, in an Internet survey of OULA ${ }^{\circledR}$, the authors report that the majority of the sample attended OULA ${ }^{\circledR}$ for 4-5 years (Hellem and Ferguson 2018). In the current study, $\mathrm{n}=30$ (56.6\% attrition rate) women dropped out of the study, mostly due to protocol non-compliance. Most studies that investigate a form of exercise as an intervention note an attrition rate between 25-50\% (Linke et al 2011). Specific to dance and dance/movement therapy studies, attrition rates appear to range between 0-32\% (LópezRodríguez et al 2017; Delextrat et al 2016; Domene et al 2016; Gao et al 2016; Pylvänäinen et al 2015; Murrock and Graor 2014; Punkanen et al 2014; Vankova et al 2014; Pinniger et al 2013; Baptista et al 2012; Bräuninger 2012; Meekums et al 2012; Pinniger et al 2012; Akandere and Demir 2011; Eyigor et al 2009; Hui et al 2009; Quiroga Murcia et al 2009; Haboush et al 2006; Jeong et al 2005; Noreau et al 1995). The majority of early terminations occurred by week 4, and these women were lost to follow up. As a result, the reasons for non-compliance were not identified. Future studies should consider a mechanism for interviewing early terminators to understand reasons for not continuing with the study.

Second, the use of a single arm design presents concerns with internal and external validity. Along those same lines, the small homogenous sample poses threats to external validity and limits generalizability. It is also important to acknowledge that offering OULA ${ }^{\circledR}$ at a single studio presents limitations with respect to instructor selection bias. As a pilot study, though, it seemed reasonable to first learn if an $\mathrm{OULA}^{\circledR}$ study was feasible, and a larger scale study of OULA $^{\circledR}$ should include more sites, in addition to a control arm. 
Third, splitting the intervention into two phases; i.e., online and studio, appears to have introduced a confounding factor. The inability to verify online attendance poses a reliability concern, and while there was not a difference in HAM-D, BAI and SHS scores between online and studio attendance for week 2, there was a significant difference at week 4 for HAM-D scores (but not for BAI and SHS scores). Even though online attendance was low at week $4(\mathrm{n}=5)$, women may have experienced a greater improvement in symptoms with attending OULA ${ }^{\circledR}$ at a studio. A comparison between the benefits of online and studio attendance would be an interesting future study to learn if the environment at a studio plays a significant role in symptom management. Finally, we did not utilize blinding in this study with respect to data collection or extraction, which may have introduced biased determination of outcomes (Karanicolas et al 2010).

\section{CONCLUSIONS}

OULA $^{\circledR}$, a form of therapeutic dance fitness, allows individuals to engage in physical activity and use dance to externalize tension that is generated by emotions. The aim of this study was to learn if 12 -weeks of OULA ${ }^{\circledR}$ was associated with a reduction in depression and anxiety severity, as well as to an increase in subjective happiness in women with depression. The findings suggest that OULA ${ }^{\circledR}$ may help alleviate depressive and anxious symptoms but does not have a consistent influence on subjective happiness. While these findings should be interpreted with caution based on the limitations of the study, mental health professionals, as well as primary care providers, could consider suggesting OULA ${ }^{\circledR}$ to depressed women as a way to manage mood symptoms. OULA ${ }^{\circledR}$ is available in several states in the United States, as well as online, and therefore accessible to most women. 


\section{AUTHOR DISCLOSURE STATEMENT}

None of the authors have conflicts of interest to declare, although, we would like to note that one of the authors attends OULA ${ }^{\circledR}$ classes. 


\section{REFERENCES}

Adam D, Ramli A, Shahar S 2016 Effectiveness of a combined dance and relaxation intervention on reducing anxiety and depression and improving quality of life among the cognitively impaired elderly. Sultan Qaboos University Medical Journal 16: e46-53. doi:

10.18295/squmj.2016.16.01.009

Akandere M, Demir B 2011 The effect of dance over depression. Collegium Anthropologicum 5: $651-656$

Alekhya P, Sriharsha M, Priya Darsini T, Reddy S, Venkata Ramudu R 2015 Treatment and disease related factors affecting non-adherence among patients on long term therapy of antidepressants. Journal of Depression and Anxiety 4: 1-6. doi: 10.4172/2167-1004.1000175 Amick HR, Gartlehner G, Gaynes BN, Forneris C, Asher GN, Morgan LC, Coker-Schwimmer E, Boland E, Lux LJ, Gaylord S, Bann C, Pierl CB, Lohr KN 2015 Comparative benefits and harms of second generation antidepressants and cognitive behavioral therapies in initial treatment of major depressive disorder: systematic review and meta-analysis. BMJ 351: h6019. doi:

10.1136/bmj.h6019

Babyak M, Blumenthal JA, Herman S, Khatri P, Doraiswamy M, Moore K, Craighead WE, Baldewicz TT, Krishnan, KR 2000 Exercise treatment for major depression: maintenance of therapeutic benefit at 10 months. Psychosomatic Medicine 62: 633-638.

Bagby RM, Ryder AG, Schuller DR, Marshall MB 2004 The Hamilton Depression Rating Scale: has the gold standard become lead weight? American Journal of Psychiatry 161: 2163-2177.

Ballenger JC 2000 Anxiety and depression: optimizing treatments. The Primary Care Companion to the Journal of Clinical Psychiatry 2: 71-79. 
Baptista AS, Villela AL, Jones A, Natour J 2012 Effectiveness of dance in patients with fibromyalgia: a randomized, single-blind, controlled study. Clinical and Experimental Rheumatology 30: 18-23.

Beck AT, Epstein N, Brown G, Steer RA 1988 An inventory for measuring clinical anxiety: psychometric properties. Journal of Consulting and Clinical Psychology 56: 893-897.

Blazer DG, Kessler RC, McGonale KA, Swartz MS 1994 The prevalence and distribution of major depression in a national community sample: The National Comorbidity Survey. American Journal of Psychiatry 151: 979-986.

Blumenthal JA, Babyak MA, Doraiswamy PM, Watkins L, Hoffman BM, Barbour KA, Herman S, Craighead WE, Brosse AL, Waugh R, Hinderliter A, Sherwood A 2007 Exercise and pharmacotherapy in the treatment of major depressive disorder. Psychosomatic Medicine 69: 587-596.

Boing L, Baptista F, Pereira GS, Sperandio FF, Moratelli J, Cardoso AA, Borgatto AF, de Azevedo Guimarães 2018 Benefits of belly dance on quality of life, fatigue, and depressive symptoms in women with breast cancer - a pilot study of a non-randomised clinical trial. Journal of Bodywork and Movement Therapies 22: 460-466. doi: 10.1016/j.jbmt.2017.10.003

Booth FW, Roberts CK, Laye MJ 2012 Lack of exercise is a major cause of chronic diseases. Comprehensive Physiology 2: 1143-1211.

Bräuninger I 2012 The efficacy of dance movement therapy group on improvement of qualiy of life: a randomized controlled trial. The Arts in Psychotherapy 39: 296-303.

Bull SA, Hu XH, Hunkeler EM, Lee JY, Ming EE, Markson LE, Fireman B 2002

Discontinuation of use and switching antidepressants: influence of patient-physician communication. JAMA 288: 1403-1409. 
Cain RA 2007 Navigating the sequenced treatment alternatives to relieve depression (STAR*D) study: Practical outcomes and implications for depression treatment in primary care. Primary Care 34: 505-519.

Carek PJ, Laibstain SE, Carek SM 2011 Exercise for the treatment of depression and anxiety. International Journal of Psychiatry in Medicine 41: 15-28.

Chiaramonte DR 1997 Mind-body therapies for primary care physicians. Primary Care: Clinics in Office Practice 24: 787-807.

Cooney GM, Dwan K, Grieg CA, Lawlor DA, Rimer J, Waugh FR, McMurdo M, Mead GE 2013 Exercise for depression (review). Cochrane Database of Systematic Reviews. doi:

10.1002/14561858.CD004366.pub6

Daley A 2008 Exercise and depression: a review of reviews. Journal of Clinical Psychology in Medical Settings 15: 140-147.

De Ayala RJ, Vonderhaff-Carlson DJ, Kim D 2005 Assessing the reliability of the Beck Anxiety Inventory Scores. Educational and Psychological Measurement 65: 742-756.

Delextrat AA, Warner S, Graham S, Neupert E 201 An 8-week exercise intervention based on Zumba improves aerobic fitness and psychological well-being in healthy women. Journal of Physical Activity and Health 13: 131-139.

Demyttenaere K, Enzlin P, Dewe W, Boulanger B, De Bie J, De Troyer W, Mesters P 2001 Compliance with antidepressants in a primary care setting, 1: beyond lack of efficacy and adverse events. Journal of Clinical Psychiatry 62: 30-33.

Domene PA, Moir HJ, Pummell E, Knox A, Easton C 2016 The health-enhancing efficacy of Zumba ${ }^{\circledR}$ fitness: an 8-week randomized controlled study. Journal of Sports Science 34: 1396404. 
Dusek JA, Benson H 2009 Mind-body medicine: a model of the comparative clinical impact of the acute stress and relaxation responses. Minnesota Medicine 92: 47-50.

Erwin-Grabner T, Goodill SW, Hill ES, Von Neida K 1999 Effectiveness of dance/movement therapy on reducing text anxiety. American Journal of Dance Therapy 21: 19-34.

Eyigor S, Karapolat H, Durmaz B, Ibisoglu U, Cakir S 2009 A randomized controlled trial of Turkish folklore dance on physical performance, balance, depression and quality of life in older women. Archives of Gerontology and Geriatrics 48: 84-8.

Fisher LB, Overholser JC, Ridley J, Braden A., Rosoff C 2015 From the outside looking in: sense of belonging, depression and suicide risk. Psychiatry Interpersonal \& Biological Processes 78: $29-41$.

Furukawa TA, Akechi T, Azuma H, Okuyama T, Higuchi T 2007 Evidence-based guidelines for interpretation of the Hamilton Rating Scale for Depression. Journal of Clinical Psychopharmacology 27: 531-533.

Gao L, Zhang L, Qi H, Petridis L 2016 Middle-aged female depression in perimenopausal period and square dance intervention. Psychiatria Danubina 28: 372-78.

Gaynes BN, Warden D, Wisniewski SR, Fava M, John Rush A 2009 What did STAR*D teach us? Results from a large-scale, practical, clinical trials for patients with depression. Psychiatric Services 60: 1439-1445.

Gilbert MD 2003 Weaving medicine back together: mind-body medicine in the twenty-first century. The Journal of Alternative and Complementary Medicine 9: 563-570.

Girgus JS, Yang K 2015 Gender and depression. Current Opinion in Psychology 4: 53-60. https://dx.doi.org/10.1016/j.copsyc.2015.01.019

Haboush A, Floyd M, Caron J, LaSota M, Alvarez K 2006 Ballroom dance lessons for geriatric depression: an exploratory study. The Arts in Psychotherapy 33: 89-97. 
Hallgren, KA 2012 Computing inter-rater reliability for observational data: an overview and tutorial. Tutorials in Quantitative Methods for Psychology 8: 23-34.

Hamilton M 1960 A rating scale for depression. Journal of Neurology, Neurosurgery \& Psychiatry 23: 56-62.

Hanson K, Webb TL, Sheeran P, Turpin G 2016 Attitudes and preferences towards self-help treatments for depression in comparison to psychotherapy and antidepressant medication. Behavioural and Cognitive Psychotherapy 44: 129-139.

Hellem TL, Ferguson H 2018 An Internet-based survey of the dance fitness program OULA ${ }^{\circledR}$. Sage Open Medicine 6: 1-12.

Hoffman BM, Babyak MA, Craighead WE, Sherwood A, Doraiswamy PM, Coons MJ, Blumenthal JA 2011 Exercise and pharmacotherapy in patients with major depression: one-year follow-up of the SMILE study. Psychosomatic Medicine 73: 127-133. doi:

10.1097/PSY.0b013e31820433a5

Horne R, Graupner L, Frost S, Weinman J, Wright SM, Hankins M 2004 Medicine in a multicultural society: the effect of cultural background on beliefs about medications. Social Science Medicine 59: 1307-1313.

Hui E, Chui BT, Woo J 2009 Effects of dance on physical and psychological well-being in older persons. Archives of Gerontology and Geriatrics 49: e45-50.

Jeong YJ, Hong SC, Lee MS, Park MC, Kim YK, Suh CM 2005 Dance movement therapy improves emotional responses and modulates neurohormones in adolescents with mild depression. International Journal of Neuroscience 115: 1711-20.

Kanekar S, Sheth CS, Ombach HJ, Olson PR, Bogdanova OV, Petersen M, Renshaw CE, Sung YH, D’Anci KE, Renshaw PF 2018 Hypobaric hypoxia exposure in rats differentially alters antidepressant efficacy of the selective serotonin reuptake inhibitors fluoxetine, paroxetine, 
escitalopram and sertraline. Pharmacology Biochemistry and Behavior 170: 25-35. doi:

10.1016/j.pbb.2018.05.002

Karanicola PJ, Farrokhyar F, Bhandari M 2010 Blinding: who, what, when, why, how? Canadian Journal of Surgery 53: 345-348.

Kessler RC 2003 Epidemiology of women and depression. Journal of Affective Disorders 74: 513.

Keyes CLM, Dhingra SS, Simones S 2010 Change in level of positive mental health as a predictor of future risk of mental illness. American Journal of Public Health 100, 2366-71. Keyes CLM 2005 Mental illness and/or mental health? Investigating axioms of the complete state model of health. Journal of Consulting and Clinical Psychology 73, 539-548. Knapen J, Vancampfort D, Moriën Y, Marchal Y 2015 Exercise therapy improves both mental and physical health in patients with depression. Disability and Rehabilitation 37: 1490-5. Kringelbach ML, Berridge KC 2011 The neuroscience of happiness and pleasure. Social Research (New York) 77: 659-678.

La Forge R 2016 Mind-body (mindful) exercise in practice. ACSM's Health \& Fitness Journal 20: 6-8.

Lawlor DA, Hopker SW 2001 The effectiveness of exercise as an intervention in the management of depression: systematic review and meta-regression analysis of randomised controlled trials. BMJ 322: 763-767.

Layard R, Chishol D, Patel VL, Saxena S Mental illness and unhappiness In: Helliwell J, Layard R, Sachs J, editors. World Happiness Report 2013. New York: Columbia University 2013: 3853.

Leisman G, Moustafa AA, Shafir T 2016 Thinking, walking, talking: integratory motor and cognitive brain function. Frontiers in Public Health 4: 1-18. 
Leon AC, Davis LL, Rogers N, Crementon E, Bonomo Y 2011 The role and interpretation of pilot studies in clinical research. Journal of Psychiatry Research 45: 626-629.

Levine B, Land HM 2016 A meta-synthesis of qualitative findings about dance/movement therapy for individuals with trauma. Qualitative Health Research 26: 330-344.

Leyfer OT, Ruberg JL, Woodruff-Borden J 2006 Examination of the utility of the Beck Anxiety Inventory and its factors as a screener for anxiety disorders. Journal of Anxiety Disorders 20: 444-458.

Linke S, Gallo LC, Norman GJ 2011 Attrition and adherence rates of sustained vs intermittent exercise interventions. Annals of Behavioral Medicine 42: 197-209.

Littrell J 2008 The mind-body connection. Social Work in Health Care 46:17-37. doi:

10.1300/J010v46n04_02

López-Rodríguez I, Ruiz-Muelle A, Cortés- Rodríguez AE, Lopezosa-Estepa T, Roman P 2017 Effects of biodanza on stress, depression and sleep quality in University students. Journal of Alternative and Complementary Medicine 23: 558-565.

Lyubomirsky S, Lepper HS 1999 A measure of subjective happiness: preliminary reliability and construct validation. Social Indicators Research 46: 137-155.

Mallinckrodt CH, Sanger TM, Dubé S, DeBrota DJ, Molenberghs G, Carroll, RJ, Potter WZ, Tollefson, GD 2003 Assessing and interpreting treatment effects in longitudinal clinical trials with missing data. Biological Psychiatry 53: 754-760. doi: 10.1016/s00063223(02)01867-x

Mattei D, Schaefer CE 2004 An investigation of validity of the Subjective Happiness Scale. Psychology Reports 94: 288-290.

Mead GE, Morley W, Campbell P, Greig CA, McMurdo M, Lawlor DA 2008 Exercise for depression. Cochrane Database of Systematic Reviews 8: CD004366. 
Meekums B, Vaverniece I, Majore-Dusele I, Rasnacs O 2012 Dance movement therapy for obese women with emotional eating: a controlled pilot study. The Arts in Psychotherapy 39: 126-133.

McGraw KO, Wong, SP 1996 Forming inferences about some intraclass correlation coefficients. Psychology Methods 1: 30-46.

McNeely ME, Duncan RP, Earhart GM 2015 Impacts of dance on non-motor symptoms, participation, and quality of life in Parkinson disease and healthy older adults. Maturitas 82: 336341. doi: 10.1016/j.maturitas.2015.08.002

Mojtabai R, Olfson M 2014 National trends in long-term use of antidepressant medications: results from the U.S. National Health and Nutrition Examination Survey. Journal of Clinical Psychiatry 75: 167-177.

Moradveusi L, Huibers M, Renner F, Arntz A 2014 The influence of patients' preference/attitude towards psychotherapy and antidepressant medication on the treatment of major depressive disorder. Journal of Behavior Therapy and Experimental Psychiatry 45: 170-177.

Moscati A, Flint J, Kendler KS 2016 Classification of anxiety disorders comorbid with major depression: common or distinct influences on risk? Depression and Anxiety 33: 120-127. Murrock CJ, Graor CH 2014 Effects of dance on depression, physical function and disability in underserved adults. Journal of Aging and Physical Activity 22: 380-385. doi: 10.1123/japa.20130003

Murrock CJ, Graor CH 2016 Depression, social isolation, and the lived experience of dancing in disadvantaged adults. Archives of Psychiatric Nursing 30: 27-34. doi:

10.1016/j.apnu.2015.10.010

Nolen-Hoeksema, S 2001 Gender differences in depression. Current Directions in Psychological Science 10: 173-176. 
Noreau L, Martineau H, Roy L, Belzile M 1995 Effects of a modified dance-based exercise on cardiorespiratory fitness, psychological state and health status of persons with rheumatoid arthritis. American Journal of Physical Medicine and Rehabilitation 74: 19-27.

Parker G, Brotchie H 2010 Gender differences in depression. International Review of Psychiatry 22: $429-436$.

Parker G, Fletcher K, Paterson A, Anderson J, Hong M 2014 Gender differences in depression severity and symptoms across depressive sub-types. Journal of Affective Disorders 167: 351357. doi: $10.1016 /$ j.jad.2014.06.018

Pedersen BK, Saltin B 2015 Exercise as medicine - evidence for prescribing exercise as therapy in 26 different chronic disease. Scandinavian Journal of Medicine \& Science in Sports 25: 1-72. doi: $10.1111 / \mathrm{sms} .12581$

Pedersen BK, Saltin B 2006 Exercise as medicine - evidence for prescribing exercise as therapy in 26 different chronic disease. Scandinavian Journal of Medicine \& Science in Sports 16: 3-63. Pinniger R, Thorsteinsson EB, Brown RF, McKinley P 2013 Intensive tango dance program for people with self-referred affective symptoms. Music Medicine 5: 15-22.

Pinniger R, Brown RF, Thorsteinsson EB, McKinley P 2012 Argentine tango dance compared to mindfulness meditation and a waiting-list control: a randomised trial for treating depression. Complementary Therapy Medicine 20: 377-384. doi: 1.1016/j.ctim.2012.07.003 Phillips J, De Fritas J, Mott C, Gruber J, Knobe J 2017 True happiness: the role of morality in the folk concept of happiness. Journal of Experimental Psychology: General 146: 165-181. Punkanen M, Saarikallio S, Luck G 2014 Emotions in motion: short-term group form Dance/Movement Therapy in the treatment of depression: a pilot study. Arts in Psychotherapy 41: 493-497. 
Pylvänäinen PM, Muotka JS, Lappalainen R 2015 A dance movement therapy group for depressed adult patients in a psychiatric outpatient clinic: effects of the treatment. Frontiers of Psychology 10: 980.

Quiora Murcia C, Bongard S, Kreutz G 2009 Emotional and neurohumoral responses to dancing tango argentine: the effects of music and partner. Music Medicine 1: 14-21.

Rosas D, Rosas C 2014 The Nia Technique: the high-powered energizing workout that gives you a new body and life. New York, NY: Broadway Books

Rosas D, Rosas C 1987 Non-impact aerobics: the NIA Technique. New York: Avon

Salk RH, Hyde JS, Abramson LY 2017 Gender differences in depression in representative national samples: meta-analyses of diagnoses and symptoms. Psychology Bulletin 143: 783-822. Sawada N, Uchida H, Suzuki T, Watanabe K, Kikichi T, Handa T, Kashima H 2009 Persistence and compliance to antidepressant treatment in patients with depression: a chart review. BMC Psychiatry 9: 38. doi: 10.1186/1471-244X-9-38.

Shivakumar G, Anderson EH, Suris AM, North CS 2017 Exercise for PTSD in women veterans: a proof-of-concept study. Military Medicine 182: e1809-e1814.

Silva RC, Figueriredo-Braga M 2018 Evaluation of the relationships among happiness, stress, anxiety, and depression in pharmacy students. Currents in Pharmacy Teaching and Learning 10: 903-910.

Sjösten N, Kivelä SL 2006 The effects of physical exercise on depressive symptoms among the aged: a systematic review. International Journal of Geriatric Psychiatry 21: 410-418.

Spinhoven P, Elzinga BM, Giltay E, Penninx B 2015 Anxious or depressed and still happy? PLOS One 10: e0139912 
Stathopoulou G, Powers MB, Berry AC, Smits JA, Otto MW 2006 Exercise interventions for mental health: a quantitative and qualitative review. Clinical Psychology: Science and Practice. 13: 179-193.

Steinberg-Oren SL, Krasnova M, Krasnova IS, Baker MR, Ames D 2016 Let's dance: a holistic approach to treating veterans with posttraumatic stress disorder. Federal Practitioner 33: 44-49. Tantia JF 2015 The interface between somatic psychotherapy and dance/movement therapy: a critical analysis. Body, Movement and Dance in Psychotherapy 11: 1-16.

Vankova H, Holmerova I, Machacova K, Volicer L, Veleta P, Celko AM 2014 The effect of dance on depressive symptoms in nursing home residents. Journal of America Medical Directive Association 15: 582-587. doi: 10.1016/j.jamda.2014.04.013

Viana RC, Alves CL, Vieira CA, Vancina RL, Campos MH, Gentil P, Andrade MS, de Lira CAB 2017 Anxiolytic effects of a single session of the exergame Zumba ${ }^{\circledR}$ fitness on healthy young women. Games for Health Journal 6: 365-370.

Vina J, Sanchis-Gomar F, Martinez-Bello V, Gomez-Cabreara MC 2012 Exercise acts as a drug: the pharmacological benefits of exercise. British Journal of Pharmacology 167: 1-12. Vuilleumier P, Trost W 2015 Music and emotions: from enhancement to entrainment. Annals of the New York Academy of Sciences, 1337: 212-222.

West BT, Welch KB, Gałecki AT 2006 Linear mixed models: A practical guide using statistical software. New York: Chapman \& Hall/CRC.

Whitworth JW, Ciccolo JT 2016 Exercise and post-traumatic stress disorder in military veterans: a systematic review. Military Medicine 181: 953-960.

World Health Organization. (2018). Depression. Available at: http://www.who.int/newsroom/fact-sheets/detail/depression 
Zimmerman DW 1987 Comparative power of Students $T$ Test and Mann-Whitney $U$ Test for unequal sample sizes and variances. Journal of Experimental Education 55: 171-174. 